・论坛・ 中国国家公园试点专题

\title{
大熊猫国家公园体制试点的经验与挑战
}

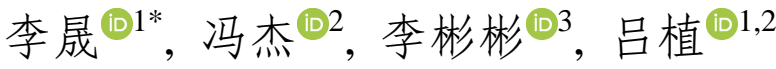

1. 北京大学生命科学学院\&生态研究中心, 北京 100871; 2. 山水自然保护中心, 北京 100871; 3. 昆山杜克大学环境研究中心, 江苏昆山 215316

李晟, 冯杰, 李彬涁, 吕植 (2021) 大熊猫国家公园体制试点的经验与挑战 生物多样性, 29, 307-311. doi: 10.17520/biods.2021074.

Li S, Feng J, Li BV, Lü Z (2021) The Giant Panda National Park: Experiences and lessons learned from the pilot. Biodiversity Science, 29, 307-311. doi: 10.17520/biods.2021074.

\section{The Giant Panda National Park: Experiences and lessons learned from the pilot}

Sheng $\mathrm{Li}^{(1 *}{ }^{*}$, Jie Feng ${ }^{(12}$, Binbin V. Li ${ }^{\circledR 3}$, Zhi Lü ${ }^{(1)}$

1 School of Life Sciences \& Institute of Ecology, Peking University, Beijing 100871

2 Shanshui Conservation Center, Beijing 100871

3 Environmental Research Center, Duke Kunshan University, Kunshan, Jiangsu 215316

大熊猫国家公园试点于2016年8月由四川、陕 西、甘肃三省人民政府联合上报《大熊猫国家公园 体制试点方案》; 2016年12月5日, 习近平总书记主 持召开中央全面深化改革领导小组第三十次会议 审议通过《大熊猫国家公园体制试点方案》; 2017 年1月31日, 中共中央办公厅、国务院办公厅印发 《大熊猫国家公园体制试点方案》；2018年10月29 日, 大熊猫国家公园管理局正式挂牌; 2018年11月, 大熊猫祁连山国家公园甘肃省管理局、大熊猫国家 公园四川省管理局、大熊猫国家公园陕西省管理局 相继挂牌; 2020年3月17日, 大熊猫国家公园管理局 印发《大熊猫国家公园管理办法(试行)》; 2020年6 月, 国家林业和草原局(国家公园管理局)印发《大熊 猫国家公园总体规划(试行)》。在试点过程中, 初步 建立起由大熊猫国家公园管理局、省管理局、管理 分局、管护站(管护总站)构成的实际管理体系, 其中 省管理局 3 个、管理分局 14 个。

大熊猫国家公园试点区面积 $27,134 \mathrm{~km}^{2}$, 分布 在3省12市(州)30县(市、区), 其中四川、陕西、甘 肃省内的面积分别为 $20,177 \mathrm{~km}^{2}$ (占总面积的 $74.36 \%) 、 4,386 \mathrm{~km}^{2}(16.16 \%) 、 2,571 \mathrm{~km}^{2}(9.48 \%)$ 。
试点区内原有各类自然保护地 81 个, 总面积 21,347 $\mathrm{km}^{2}$ (扣除交叉重叠部分), 占试点区总面积的 78.67\% (Huang et al, 2020)。

\section{关键经验}

大熊猫国家公园试点实施期间, 在管理体制创 新、决策咨询机制创建、跨区联合、司法协作等方 面均进行了深入的摸索与实践, 取得了多方面的成 效与经验。其中, 以下几方面的试点经验尤其突出, 具有较好的示范与推广价值。

\section{1 充分体现原真性与完整性}

在首批10个国家公园体制试点中，大熊猫国家 公园试点面积广大, 仅次于三江源 $\left(123,100 \mathrm{~km}^{2}\right)$ 与 祁连山(50,237 $\left.\mathrm{km}^{2}\right)$ 试点区(藏振华等, 2020)。充足 的面积确保了国家公园试点能够充分体现以大熊 猫(Ailuropoda melanoleuca)为代表的山地生态系统 的原真性与完整性。根据全国第四次大熊猫调查结 果, 试点区范围覆盖了野生大熊猫种群数量的 $87.50 \%$ (约1,631只)和大熊猫栖息地面积的 $70.25 \%$ $\left(18,101 \mathrm{~km}^{2}\right)$, 同时覆盖了至少641个脊椎动物物种 和3,446个植物物种的栖息地(Huang et al, 2020)。虽

收稿日期: 2021-03-01; 接受日期: 2021-03-11

基金项目: 生态环境部生物多样性调查、观测与评估项目(2019HJ2096001006)

* 通讯作者 Author for correspondence. E-mail: shengli@pku.edu.cn 
然大熊猫国家公园试点以单一旗舰物种大熊猫命 名, 但已有研究显示, 以大熊猫为目标物种的保护 投入可以惠及与之同域分布的其他大量野生动植 物物种(Li \& Pimm, 2016), 同时带来价值可观且多 样的生态系统服务(Wei et al, 2018)。

\section{2 积极探索社区共建共管, 创新管理体制}

《大熊猫国家公园体制试点方案》指出, 坚持 开放合作理念, 创新生态保护管理机制, 强调全民 参与, 共建共享, 引导当地居民、社会组织、国际 社会参与, 形成全社会共建共管新模式, 完善当地 居民参与生态保护的利益分配机制和多元化生态 补偿机制，探索可持续的社区发展机制，促进人与 自然和谐共生。

在试点过程中, 大熊猫国家公园结合已有的工 作基础，广泛联合保护NGO、当地社区、公益基金 会和企业等多方力量与利益相关者, 通过建立保护 小区、创建社区保护与巡护队伍、建立社区公益基 金支持居民发展生态友好型生计与产业等多种途 径, 进行了社区共建共管的尝试, 成功建立老河沟 公益保护地、关坝保护小区等示范模式(Jin, 2018; 王伟和李俊生，2021), 尝试构建“公园管理机构-村 级组织-公益组织”三位一体格局(㶓振华等, 2020), 并在共建共管共享实践的基础上总结经验，形成 《大熊猫国家公园社区建设典型案例集》。在分局 层面试点建立共管理事会, 丰富社会各界参与支持 大熊猫国家公园建设发展的方式与途径。在怅山区 域试点四川、甘肃两省多县跨行政区域的联合行动, 最大的亮点是将区内的 9 个以社区、社会组织为主 体进行管理的自然保护地加入进来，从原来的“对 手”变成现在的“战友”, 共建共管联合行动, 共同保 护大熊猫栖息地。在大熊猫国家公园内和入口社区 开展“蚂蚁森林” 公益保护地试点, 上线关坝、福寿 两个社区保护地, 认领公众 3,059 万人次, 获得社会 资金 440 余万元支持今后 10 年的生态保护与绿色发 展, 探索政府购买社区生态保护服务机制, 为生态 公益岗位设置积累经验。试点期间采取区别于自然 保护区建设的理念, 用疏通代替围堵, 用融合代替 部分搬迁, 用共建代替死守的方式进行生态保护管 理。这些创新的管理体制为充分调动多方社会资源 投入国家公园的保护与管理提供了有益的尝试, 同 时探索了如何在国家公园的社区管理中妥善处理 保护与发展的关系, 调动当地社区参与公园管理的
积极性, 对于其他国家公园体制试点区具有非常重 要的借鉴价值(吕植等, 2015; Jin, 2018; 藏振华等, 2020)。

大熊猫国家公园试点与管理绕不开社区参与, 更离不开社区参与。社区是大熊猫国家公园的重要 组成部分, 是大熊猫栖息地实现完整性、连通性的 重点和难点。在新的生态保护机制和配套政策下, 社区正逐渐成为大熊猫国家公园建设的生力军。

\section{3 建立并持续完善系统化、标准化的野生动物监 测体系}

生物多样性监测是国家公园保护的核心基础 之一(米湘成, 2019)。得益于20世纪60年代以来国家 与国际社会对大熊猫这一旗舰物种及其栖息地保 护的大力投入, 国家公园试点启动之前, 试点区范 围内已建立起以自然保护区为主要类型的众多自 然保护地, 在秦岭、岷山、工崃山等片区已经形成 相互连片的区域性自然保护区群(Li et al, 2010; Yang et al, 2020)。以这些大熊猫保护地为基础, 结 合历次全国大熊猫调查, 该区域建立了较为系统的 针对野生大熊猫种群、栖息地及伴生动物的监测体 系(国家林业局，2006; 四川省林业厅，2015)。试点 区也是我国最早开展大规模野生动物红外相机监 测的地区(Li et al, 2010); 经过十多年的发展, 在国 家公园试点实施期间, 试点区内已经建立起较为标 准化的红外相机监测网络, 目前布设有红外相机近 1万台(Li et al, 2020; 李戟等, 2020)。以大熊猫保护 区公里网格监测规程为核心的监测方案经整理、完 善后, 以行业地方标准的形式正式发布, 即《四川 省地方标准: 野生动物红外相机监测技术规程》 (DB51/T2287-2016) (李晟等, 2020), 为国家公园标 准化野生动物监测体系的构建奠定了基础。这样的 监测体系建设, 不仅为区内的生物多样性编目与监 测构建了可靠的基础, 也在近年来诸多科研成果的 产出中起到了关键的作用, 同时为保护地的保护成 效评估(Shen et al, 2020)、景观廊道规划(Wang et al, 2014)、保护管理决策等提供了科学的支撑。

\section{问题与挑战}

\section{1 管理体制与运行机制仍有待理顺, 各级管理} 机构的责权利需要澄清

大熊猫国家公园试点虽然确立了“管理局、省 管理局、管理分局、管护站”的4级管理架构, 但在 
实际工作中, 还未建立起自上而下、统一领导的运 行机制与管理体制, 公园管理局缺乏有效实施管理 的各项职权。在试点过程中, 大熊猫国家公园由中 央与地方共同管理, 但中央(例如国家林业和草原 局、国家公园管理局)与地方(例如省级林业和草原 局、国家公园省管理局)之间在权责、财务、人事等 方面的管理体制还未完全理顺。各级地方管理机构 对各自所需承担的职责和所拥有的权利不甚明了, 国家公园范围内的保护区依旧按照原有管理机制 运行, 且普遍认为试点实施期间乃至国家公园正式 建立之后，自身将面临承担责任增大而可用资源有 限甚至减少的困境。管理人员普遍感到目前责任与 权利不相匹配, 这已经成为各级地方管理机构缺乏 积极性、主动性的内在机制性问题。

\section{2 跨省共建与管理难度大}

大熊猫国家公园范围大、涉及广，区内原有的 众多自然保护地性质、级别构成复杂, 空间重叠与 管理部门交叉程度较高(马童慧等, 2019; Yang et al, 2020); 在此基础上, 区内还有50个国有林场、15个 森工企业、3个省属林业局, 需要结合实际情况分类 处置。各省片区之间, 在以往的行政体系、人事设 置、办事流程、管理方式与风格上均具有较大差异, 其背后既有各种历史原因也有现实客观限制, 目前 形成了事实上的三省分治管理格局, 进行跨省共建 与管理协调的难度大。尤其是陕西省秦岭片区, 由 于在地理位置上相对孤立, 大熊猫栖息地和种群与 其他片区相隔离, 此外保护面临的威胁有所区别, 因而难以与四川和甘肃形成联合管理机制。如果各 省片区之间长期难以形成统一, 将来有可能出现各 片区各行其是、公园管理局难以统领的局面。

\section{3 社区发展与保护的矛盾仍是国家公园面临的 主要挑战}

试点区涉及四川、陕西、甘肃的12个市(州)、 30 个县(市、区)、 152 个乡镇, 共 12.08 万人, 其中常 住人口 8.51 万人, 有藏族、彝族、芫族、回族等 19 个少数民族, 核心保护区内现有居民 5,500 人以上 (Huang et al, 2020); 区内集体土地面积7,758 $\mathrm{km}^{2}$, 占总面积的 $28.59 \%$ 。相较于其他国家公园试点, 大 熊猫国家公园试点区社区人数多、贫困程度高、文 化多样性强、传统知识丰富、生产生活与自然资源 关系紧密。区内及周边居民采集薪柴、散放家畜等 人为活动仍是大熊猫栖息地内重要的干扰类型
(Hull et al, 2014; Wang et al, 2015; Li et al, 2017)。作 为主要生计来源, 很多生产活动(例如放牧)存在涉 及面广、涉及人群贫富差距大、贫困人口缺乏其他 替代生计等问题, 保护与发展的冲突问题严重。除 国家公园建设外，该地区不同政策间还存在相互矛 盾的问题。例如一些扶贫项目缺乏对生态影响的考 量, 其通过小额贷款等方式促进社区畜牧业发展, 有可能加剧人类活动干扰对熊猫栖息地的影响。试 点区内及周边生活有大量的居民，存在多样的人类 活动与干扰, 野生动物与当地社区生产生活冲突高 发, 土地与林地权属复杂, 矿山和水电等产业退出 后的补偿与就业安置困难, 生态产品价值实现方式 较为单一, 地区间的区域发展水平差异巨大等, 这 些因素都将给国家公园后续的有效管理带来非常 大的挑战。国家公园内可持续生计发展需要各级管 理部门联合地方政府与社区投入较多的精力与资 源, 并针对各地的具体情况, 制定精细化、差异化 的管理策略与措施。

\section{4 人员编制亟待加强与优化}

由于诸多历史原因, 国家公园试点区内原有保 护地的人员编制数量存在明显的区域性不均衡。试 点区内原有保护地、林场、森工企业等单位的在职 职工、临聘职工与离退休人员数量庞大, 这些人员 的安置、分流需要公园管理机构与各级政府投入大 量资源与精力, 多方通力合作, 共同解决。国家公 园从事一线巡护、监测等日常工作的人员中, 普遍 存在年龄偏大、教育程度偏低的问题。同时, 大量 一线工作人员为临聘制或其他非正式人员(如“天保 工程”聘用人员), 在现行的人事招聘、考核与管理 制度下, 较难甚至无法获得正式编制, 从而可能影 响试点前后人员队伍的持续性、稳定性和工作积极 性。现有编制及招聘、考核、薪酬制度需要突破原 有体制，并配套当地政策，吸引不同类型人才顺利 进入国家公园系统，长期从事一线巡护、科学研究、 管理等不同岗位的工作。

\section{5 需持续重视栖息地破碎化问题与连通性恢复}

由于自然地形与长期以来各类人类活动和基 础设施建设的影响, 大熊猫国家公园试点区内栖息 地整体上破碎化较为严重。区内大熊猫栖息地和种 群被隔离成18个斑块和局域种群, 其中种群数量大 于 100 只的有 6 个, 主要分布在岷山中部、邛崃山中 北部和秦岭中部; 种群数量 30-100只的有 2 个; 种 
群数量小于 30 只的有 10 个。过去数十年间, 大熊猫 野生种群及其栖息地的保护取得了显著的成效, 野 生大熊猫的种群数量与栖息地面积在 20 世纪中后 期持续下降的趋势得以扭转, 并在近 20 年来恢复增 长, 整体受威胁状况得到极大改善(Yang et al, 2017; Swaisgood et al, 2018; Wei et al, 2018)。但与此同时, 大熊猫栖息地斑块的破碎化程度却仍在加剧(Xu et al, 2017; Yang et al, 2017)。体制试点实施以来，栖息 地破碎化问题及景观廊道的恢复持续得到重视, 通 过部分区域生态走廊的建设, 大熊猫栖息地的破碎 化得到了一定程度的修复; 再加上近年来重引入项 目的顺利实施, 为部分大熊猫隔离小种群的复壮与 种群间交流创造了有利条件(Yang et al, 2018)。但长 远来看, 试点区内栖息地的破碎化问题和栖息地斑 块之间连通性的恢复, 是国家公园今后需长期投入 和解决的关键问题。在大熊猫国家公园试点方案中, 没有包括大小凉山以及岷山北部的小种群。这些小 种群的继续生存, 特别是如何与国家公园内的核心 种群维持或恢复基因交流, 关乎整个大熊猫野生种 群的健康, 也应是国家公园规划和建设中需要考虑 的内容。

大熊猫国家公园取得的经验可供其他国家公 园和保护地借鉴，而从宏观的角度来看，我国首批 国家公园试点均面临一些共性问题。例如: (1)国家 公园立法还未完成，相关法律法规的缺位导致对新 划入国家公园范围的(非保护区)区域的管理缺乏法 律依据。(2)在试点实施期间, 在国家层面上没有增 加人员编制，未来是否有这方面的考虑尚不得知。 (3)国家公园试点期间及正式建立之后, 其长期运行 与管理所需的资金来源与规划、使用机制仍未建立, 未能体现出试点方案中所提出的以中央财政为主 的资金运行机制。如果人与钱这两个基本要素存在 较大的不确定性, 将会给国家公园对人才的吸引力 和长效管理机制带来很大挑战。(4)这些试点区均存 在由于历史上人类活动带来的不同程度的生态系 统退化与破碎化问题, 并面临当前和今后的气候变 化等大尺度环境变化和社会经济快速发展所带来 的潜在影响。如何对区内生态系统、动植物种群、 栖息地的恢复与修复进行长远规划, 有效纳入国家 公园的长期保护目标与管理计划之中, 并与国家或 地方的其他生态保护工程及政策相结合, 也是今后 以国家公园为主体的新的自然保护地体系建设过
程中需要考虑和解决的问题。

致谢: 感谢大熊猫国家公园管理局、各省管理局与 区内保护地工作人员提供的大量基础材料与信息。 感谢张黎明、古晓东、张晓峰、蒋仕伟参与讨论并 提供宝贵建议。

\section{ORCID}

李晟 (D) https://orcid.org/0000-0001-7200-9539

冯杰 (D) https://orcid.org/0000-0003-2680-6080

李彬须 (D) https://orcid.org/0000-0001-6188-7512

吕植 (D) https://orcid.org/0000-0001-7428-2846

\section{参考文献}

Huang QY, Fei YX, Yang HB, Gu XD, Songer M (2020) Giant Panda National Park, a step towards streamlining protected areas and cohesive conservation management in China. Global Ecology and Conservation, 22, e00947.

Hull V, Zhang JD, Zhou SQ, Huang JY, Viña A, Liu W, Tuanmu MN, Li RG, Liu D, Xu WH, Huang Y, Ouyang ZY, Zhang HM, Liu JG (2014) Impact of livestock on giant pandas and their habitat. Journal for Nature Conservation, 22, 256-264.

Jin T (2018) China’s Land Trust Reserves. In: Guidelines for Privately Protected Areas (ed. Mitchell BA). Best Practice Protected Area Guidelines Series No. 29. IUCN, Gland, Switzerland.

Li BV, Pimm SL (2016) China's endemic vertebrates sheltering under the protective umbrella of the giant panda. Conservation Biology, 30, 329-339.

Li BV, Pimm SL, Li S, Zhao LJ, Luo CP (2017) Free-ranging livestock threaten the long-term survival of giant pandas. Biological Conservation, 216, 18-25.

Li S (2020) Development progress and outlook of the wildlife camera-trapping networks in China. Biodiversity Science, 28, 1045-1048. (in Chinese) [李晟 (2020) 中国野生动物 红外相机监测网络建设进展与展望. 生物多样性, 28 , 1045-1048.]

Li S, McShea WJ, Wang DJ, Gu XD, Zhang XF, Zhang L, Shen XL (2020) Retreat of large carnivores across the giant panda distribution range. Nature Ecology \& Evolution, 4, 1327-1331.

Li S, McShea WJ, Wang DJ, Shen XL, Bu HL, Guan TP, Wang F, Gu XD, Zhang XF, Liao HH (2020) Construction progress of the Camera-trapping Network for the Mountains of Southwest China. Biodiversity Science, 28, 1049-1058. (in Chinese with English abstract) [李晟, McShea WJ, 王大 军, 申小莉, 卜红亮, 官天培, 王放, 古晓东, 张晓峰, 廖 影泓 (2020) 西南山地红外相机监测网络建设进展. 生 物多样性, 28, 1049-1058.] 
Li S, Wang DJ, Gu XD, McShea WJ (2010) Beyond pandas, the need for a standardized monitoring protocol for large mammals in Chinese nature reserves. Biodiversity and Conservation, 19, 3195-3206.

Lü Z, Gu L, Wen C, Wang H, Zhong J (2015) China Nature Watch 2014: An independent report on China's biodiversity conservation status. Biodiversity Science, 23, 570-574. (in Chinese with English abstract) [吕植, 顾垒, 闻丞, 王昊, 钟嘉 (2015) 中国自然观察2014: 一份关于中国生物多 样性保护的独立报告. 生物多样性, 23, 570-574.]

Ma TH, Lü C, Lei GC (2019) The spatial overlapping analysis for China's natural protected area and countermeasures for the optimization and integration of protected area system. Biodiversity Science, 27, 758-771. (in Chinese with English abstract) [马童慧, 吕偲, 雷光春 (2019) 中国自然保护地 空间重叠分析与保护地体系优化整合对策. 生物多样性, 27, 758-771.]

Mi XC (2019) Biodiversity monitoring and research are basis of national park conservation. Biodiversity Science, 27, 1-4. (in Chinese) [米湘成 (2019) 生物多样性监测与研究是国 家公园保护的基础. 生物多样性, 27, 1-4.]

Shen XL, Li S, McShea WJ, Wang DJ, Yu JP, Shi XG, Dong W, Mi XC, Ma KP (2020) Effectiveness of management zoning designed for flagship species in protecting sympatric species. Conservation Biology, 34, 158-167.

Sichuan Forestry Department (2015) The Pandas of Sichuan: The 4th Survey Report on Giant Panda in Sichuan Province. Sichuan Science and Technology Press, Chengdu. (in Chinese) [四川省林业厅 (2015) 四川的大熊猫: 四川省 第四次大熊猫调查报告. 四川科学技术出版社, 成都.]

State Forestry Administration (2006) The 3rd National Survey Report on Giant Panda in China. Science Press, Beijing. (in Chinese) [国家林业局 (2006) 全国第三次大熊猫调查报 告. 科学出版社, 北京.]

Swaisgood RR, Wang DJ, Wei FW (2018) Panda downlisted but not out of the woods. Conservation Letters, 11, e12355.

Wang F, McShea WJ, Wang DJ, Li S (2015) Shared resources between giant panda and sympatric wild and domestic mammals. Biological Conservation, 186, 319-325.

Wang F, McShea WJ, Wang DJ, Li S, Zhao Q, Wang H, Lü Z (2014) Evaluating landscape options for corridor restoration between giant panda reserves. PLoS ONE, 9, e105086.

Wang W, Li JS (2021) In-situ conservation of biodiversity in China: Advances and prospects. Biodiversity Science, 29, 133-149. (in Chinese with English abstract) [王伟, 李俊生 (2021) 中国生物多样性就地保护成效与展望. 生物多样 性, 29, 133-149.]

Wei FW, Costanza R, Dai Q, Stoeckl N, Gu XD, Farber S, Nie YG, Kubiszewski I, Hu YB, Swaisgood R, Yang XY, Bruford M, Chen YP, Voinov A, Qi DW, Owen M, Yan L, Kenny DC, Zhang ZJ, Hou R, Jiang SW, Liu HB, Zhan XJ, Zhang L, Yang B, Zhao LJ, Zheng XG, Zhou WL, Wen YL, Gao HR, Zhang W (2018) The value of ecosystem services from giant panda reserves. Current Biology, 28, 2174-2180.

Xu WH, Viña A, Kong LQ, Pimm SL, Zhang JJ, Yang W, Xiao Y, Zhang L, Chen XD, Liu JG, Ouyang ZY (2017) Reassessing the conservation status of the giant panda using remote sensing. Nature Ecology \& Evolution, 1, 1635-1638.

Yang B, Qin SY, Xu WS, Busch J, Yang XY, Gu XD, Yang ZS, Wang B, Dai Q, Xu Y (2020) Gap analysis of giant panda conservation as an example for planning China's national park system. Current Biology, 30, 1287-1291.

Yang HB, Viña A, Tang Y, Zhang JD, Wang F, Zhao ZQ, Liu JG (2017) Range-wide evaluation of wildlife habitat change: A demonstration using giant pandas. Biological Conservation, 213, 203-209.

Yang ZS, Gu XD, Nie YG, Huang F, Huang Y, Dai Q, Hu YB, Yang Y, Zhou X, Zhang HM, Yang XY, Wei FW (2018) Reintroduction of the giant panda into the wild: A good start suggests a bright future. Biological Conservation, 217, 181-186.

Zang ZH, Zhang D, Wang N, Du A, Kong LQ, Xu WH, Ouyang ZY (2020) Experiences, achievement, problems and recommendations of the first batch of China's national park system pilots. Acta Ecologica Sinica, 40, 8839-8850. (in Chinese with English abstract) [㶓振华, 张多, 王楠, 杜傲, 孔令桥, 徐卫华, 欧阳志云 (2020) 中国首批国家公园体 制试点的经验与成效、问题与建议. 生态学报, 40, 8839-8850.]

(责任编委: 徐卫华 责任编辑: 时意专) 